\title{
A Generalisation of Fuzzy Soft Max-Min Decision-Making Method and Its Application to a Performance-Based Value Assignment in Image Denoising
}

\author{
Serdar ENGINOĞLU ${ }^{1, *}$, Samet MEMIŞ ${ }^{1}$, Naim ÇAĞMAN ${ }^{2}$ \\ ${ }^{1}$ Department of Mathematics, Faculty of Arts and Sciences, Çanakkale Onsekiz Mart University, \\ Çanakkale/Turkey \\ ${ }^{2}$ Department of Mathematics, Faculty of Arts and Sciences, Tokat Gaziosmanpaşa University, Tokat/Turkey \\ serdarenginoglu@gmail.com
}

Received/Geliş: 09.04.2019

Accepted/Kabul: 12.06.2019

\begin{abstract}
Latterly, the fuzzy soft max-min decision-making method denoted by FSMmDM and provided in [Çağman, N., Enginoğlu, S., Fuzzy soft matrix theory and its application in decision making, Iranian Journal of Fuzzy Systems, 2012, 9(1), 109-119] has been configured via fuzzy parameterized fuzzy soft matrices ( $f p f s$ matrices) by Enginoğlu and Memiş [A configuration of some soft decision-making algorithms via $f p f s$ matrices, Cumhuriyet Science Journal, 2018, 39(4), 871-881], faithfully to the original. Although this configured method denoted by CE12 and constructed by and-product/or-product (CE12a/CE12o) is useful in decisionmaking, the method should be made more attractive in terms of time and complexity in the event that a large amount of data is processed. In this paper, we propose two algorithms denoted by EMC19a and EMC19o and being new generalisations of FSMmDM. Moreover, we prove that EMC19a accept CE12a as a special case in the event that the first rows of the $f p f s$-matrices are binary. Afterwards, we compare the running times of these algorithms. The results show that EMC19a and EMC19o outperform CE12a and CE12o, respectively, in any number of data. We then apply EMC19o to a decision-making problem in image denoising. Finally, we discuss the need for further research.
\end{abstract}

Keywords: Fuzzy sets, soft sets, soft decision-making, soft matrices, $f p f s$-matrices

\section{Bulanık Esnek Maks-Min Karar Verme Metodunun Bir Genelleştirmesi ve Gürültü Kaldırmada Performans Temelli Değer Atamaya Uygulaması}

Öz: Son zamanlarda, FSMmDM ile gösterilen ve [Çağman, N., Enginoğlu, S., Fuzzy soft matrix theory and its application in decision making, Iranian Journal of Fuzzy Systems, 2012, 9(1), 109-119] çalışmasında verilen bulanık esnek maks-min karar verme metodu, Enginoğlu ve Memiş [A configuration of some soft decision-making algorithms via $f p f s$-matrices, Cumhuriyet Science Journal, 2018, 39(4), 871-881] tarafindan bulanık parametreli bulanık esnek matrisler ( $f p f s$-matrisler) yoluyla orijinaline sadık kalacak biçimde yapılandırıldı. CE12 ile gösterilen ve ve-çarpım/veya-çarpım (CE12a/CE12o) yoluyla inşa edilen bu yapılandırılmış metot karar vermede kullanışlı olmasına rağmen, yüksek sayıda veri işlenirken zaman ve karmaşıklık bakımından daha cazip hale getirilmesi gerekmektedir. Bu çalışmada, FSMmDM'nin genelleştirmeleri olan ve EMC19a ve EMC19o ile gösterilen iki algoritma öneriyoruz. Ayrıca, EMC19a'nın fpfs-matrislerin ilk satırlarındaki bileşenlerin 0 ya da 1 olduğunda CE12a'yı özel bir durum olarak kabul ettiğini gösteriyoruz. Ardından, bu algoritmaların çalışma sürelerini karşılaştırıyoruz. Sonuçlar herhangi bir veri sayısında EMC19a ve EMC19o'nun sırasıyla CE12a ve CE12o'dan daha iyi bir performans sergilediğini göstermektedir. Daha sonra, EMC19o'yu gürültü kaldırmada bir karar verme problemine uyguluyoruz. Son olarak, sonraki çalışmalar hakkında bir tartışmaya yer veriyoruz.

Anahtar Kelimeler: Bulanık kümeler, esnek kümeler, esnek karar verme, esnek matrisler, $f p f s$-matrisler

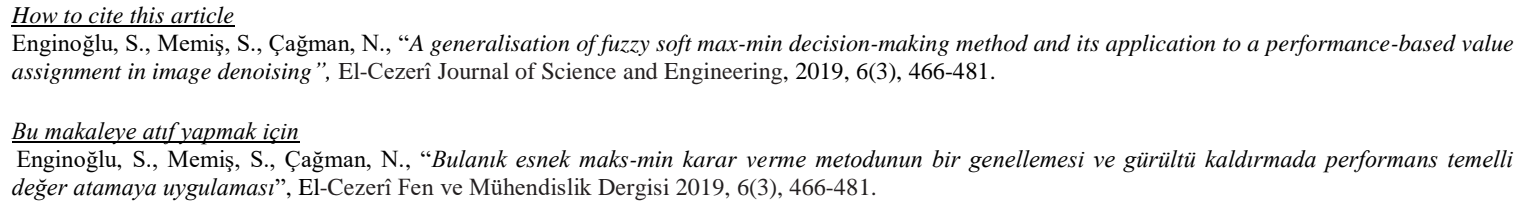

Enginoğlu, S., Memiş, S., Çağman, N., "A generalisation of fuzzy soft max-min decision-making method and its application to a performance-based value assignment in image denoising", El-Cezerî Journal of Science and Engineering, 2019, 6(3), 466-481. 


\section{Introduction}

Soft sets [1] are designed to cope with uncertainties, and so far, many applied and theoretical studies have been conducted on that [2-33]. Recently, some soft decision-making algorithms have been configured via fuzzy parameterized fuzzy soft matrices ( $f p f s$-matrices) by Enginoğlu and Memiş [34], faithfully to the original. Moreover, the authors have remarked that studies on the simplifications and different configurations of these methods therein are worth doing. In the recent time, several soft decision-making algorithms given in [34] have been configured and simplified [35-39] to apply them to a decision-making problem in computer science such as image denoising and machine learning.

The soft max-min decision-making method SMmDM and the fuzzy soft max-min decision-making method FSMmDM provided in [5,12] and configured in [34] have a similar disadvantage considered in [35-39]. Therefore, in this paper, we have focused on improving two new methods being a different generalisation of them and free of the disadvantages mentioned above.

In Section 2, we present the concept of $f p f s$-matrices [13,40] and give CE12 constructed by andproduct/or-product (CE12a/CE12o) [5,12,34]. In Section 3, we propound two new methods, namely EMC19a and EMC19o, and prove that EMC19a equivalent to CE12a under the condition that first rows of the $f p f s$-matrices are binary. In Section 4, we compare the running times of these algorithms. In Section 5, we apply EMC19o to a decision-making problem in which the noise removal/image denoising methods can be ordered in terms of performance. Finally, we discuss the need for further research.

\section{Preliminaries}

In this section, firstly, the concept of $f p f s$-matrices $[13,40]$ and some of its basic definitions have been presented. Throughout this paper, let $E$ be a parameter set, $F(E)$ be the set of all fuzzy sets over $E$, and $\mu \in F(E)$. Here, a fuzzy set is denoted by $\left\{{ }^{\mu(x)} x: x \in E\right\}$ instead of $\{(x, \mu(x)): x \in$ $E$.

Definition 2.1. [7,13] Let $U$ be a universal set, $\mu \in F(E)$, and $\alpha$ be a function from $\mu$ to $F(U)$. Then, the set $\left\{\left({ }^{\mu(x)} x, \alpha\left({ }^{\mu(x)} x\right)\right): x \in E\right\}$ being the graphic of $\alpha$ is called a fuzzy parameterized fuzzy soft set ( $f p f$ s-set) parameterized via $E$ over $U$ (or briefly over $U$ ).

In the present paper, the set of all $f p f s$-sets over $U$ is denoted by $F P F S_{E}(U)$. In $F P F S_{E}(U)$, since the $\operatorname{graph}(\alpha)$ and $\alpha$ generated each other uniquely, the notations are interchangeable. Therefore, as long as it does not cause any confusion, we denote an $f p f s$-set $\operatorname{graph}(\alpha)$ by $\alpha$.

Example 2.1. Let $E=\left\{x_{1}, x_{2}, x_{3}, x_{4}\right\}$ and $U=\left\{u_{1}, u_{2}, u_{3}, u_{4}, u_{5}\right\}$. Then,

$$
\alpha=\left\{\left({ }^{0} x_{1},\left\{{ }^{0.3} u_{1},{ }^{0.7} u_{4}\right\}\right),\left({ }^{0.5} x_{2},\left\{{ }^{0.4} u_{2},{ }^{0.8} u_{3},{ }^{1} u_{5}\right\}\right),\left({ }^{0.7} x_{3},\left\{{ }^{0.4} u_{1},{ }^{0.7} u_{3},{ }^{0.8} u_{4}\right\}\right),\left({ }^{1} x_{4},\left\{{ }^{0.9} u_{3},{ }^{0.6} u_{5}\right\}\right)\right\}
$$

is an $f p f s$-set over $U$.

Definition 2.2. $[13,40]$ Let $\alpha \in F P F S_{E}(U)$. Then, $\left[a_{i j}\right]$ is called the matrix representation of $\alpha$ (or briefly fpfs-matrix of $\alpha$ ) and is defined by 
such that

$$
\left[a_{i j}\right]:=\left[\begin{array}{llllll}
a_{01} & a_{02} & a_{03} & \ldots & a_{0 n} & \ldots \\
a_{11} & a_{12} & a_{13} & \ldots & a_{1 n} & \ldots \\
\vdots & \vdots & \vdots & \ddots & \vdots & \vdots \\
a_{m 1} & a_{m 2} & a_{m 3} & \ldots & a_{m n} & \ldots \\
\vdots & \vdots & \vdots & \ddots & \vdots & \vdots
\end{array}\right] \text { for } i \in\{0,1,2, \cdots\} \text { and } j \in\{1,2, \cdots\}
$$

$$
a_{i j}:= \begin{cases}\mu\left(x_{j}\right), & i=0 \\ \alpha\left({ }^{\mu\left(x_{j}\right)} x_{j}\right)\left(u_{i}\right), & i \neq 0\end{cases}
$$

Here, if $|U|=m-1$ and $|E|=n$, then $\left[a_{i j}\right]$ has order $m \times n$.

From now on, the set of all $f p f s$-matrices parameterized via $E$ over $U$ is denoted by $F P F S_{E}[U]$.

Example 2.2. Let's consider the fpfs-set $\alpha$ provided in Example 2.1. Then, the fpfs-matrix of $\alpha$ is as follows:

$$
\left[a_{i j}\right]=\left[\begin{array}{llll}
0 & 0.5 & 0.7 & 1 \\
0.3 & 0 & 0.4 & 0 \\
0 & 0.4 & 0 & 0 \\
0 & 0.8 & 0.7 & 0.9 \\
0.7 & 0 & 0.8 & 0 \\
0 & 1 & 0 & 0.6
\end{array}\right]
$$

Definition 2.3. $[13,40]$ Let $\left[a_{i j}\right] \in \operatorname{FPFS}_{E}[U]$. For all $i$ and $j$, if $a_{i j}=\lambda$, then $\left[a_{i j}\right]$ is called $\lambda$ fpfs-matrix and is denoted by [ $\lambda]$. Here, [0] is called empty fpfs-matrix and [1] is called universal fpfs-matrix.

Definition 2.4. $[13,40]$ Let $\left[a_{i j}\right],\left[b_{i j}\right],\left[c_{i j}\right] \in F P F S_{E}[U], I_{E}:=\left\{j: x_{j} \in E\right\}$, and $R \subseteq I_{E}$. If

$$
c_{i j}:= \begin{cases}a_{i j}, & j \in R \\ b_{i j}, & j \in I_{E} \backslash R\end{cases}
$$

then $\left[c_{i j}\right]$ is called $R b$-restriction of $\left[a_{i j}\right]$ and is denoted by $\left[\left(a_{R b}\right)_{i j}\right]$. Briefly, if $\left[b_{i j}\right]=[0]$, then $\left[\left(a_{R}\right)_{i j}\right]$ can be used instead of $\left[\left(a_{R 0}\right)_{i j}\right]$. It is clear that

$$
\left(a_{R}\right)_{i j}=\left\{\begin{array}{cc}
a_{i j}, & j \in R \\
0, & j \in I_{E} \backslash R
\end{array}\right.
$$

Definition 2.5. $[13,40]$ Let $\left[a_{i j}\right],\left[b_{i j}\right] \in \operatorname{FPFS}_{E}[U]$. For all $i$ and $j$,

If $a_{i j} \leq b_{i j}$, then $\left[a_{i j}\right]$ is called a submatrix of $\left[b_{i j}\right]$ and is denoted by $\left[a_{i j}\right] \widetilde{\subseteq}\left[b_{i j}\right]$,

If $a_{i j}=b_{i j}$, then $\left[a_{i j}\right]$ and $\left[b_{i j}\right]$ are called equal fpfs-matrices and is denoted by $\left[a_{i j}\right]=\left[b_{i j}\right]$.

Definition 2.6. $[13,40]$ Let $\left[a_{i j}\right],\left[b_{i j}\right],\left[c_{i j}\right] \in \operatorname{FPFS}_{E}[U]$. For all $i$ and $j$,

If $c_{i j}:=\max \left\{a_{i j}, b_{i j}\right\}$, then $\left[c_{i j}\right]$ is called union of $\left[a_{i j}\right]$ and $\left[b_{i j}\right]$ and is denoted by $\left[a_{i j}\right] \widetilde{\cup}\left[b_{i j}\right]$,

If $c_{i j}:=\min \left\{a_{i j}, b_{i j}\right\}$, then $\left[c_{i j}\right]$ is called intersection of $\left[a_{i j}\right]$ and $\left[b_{i j}\right]$ and is denoted by $\left[a_{i j}\right] \widetilde{\cap}\left[b_{i j}\right]$,

If $c_{i j}:=\max \left\{0, a_{i j}-b_{i j}\right\}$, then $\left[c_{i j}\right]$ is called difference between $\left[a_{i j}\right]$ and $\left[b_{i j}\right]$ and is denoted by $\left[a_{i j}\right] \widetilde{\Upsilon}\left[b_{i j}\right]$,

If $c_{i j}:=\left|a_{i j}-b_{i j}\right|$, then $\left[c_{i j}\right]$ is called symmetric difference between $\left[a_{i j}\right]$ and $\left[b_{i j}\right]$ and is denoted by $\left[a_{i j}\right] \tilde{\Delta}\left[b_{i j}\right]$.

Definition 2.7. $[13,40]$ Let $\left[a_{i j}\right],\left[b_{i j}\right] \in \operatorname{FPFS}_{E}[U]$. For all $i$ and $j$, if $b_{i j}:=1-a_{i j}$, then $\left[b_{i j}\right]$ is complement of $\left[a_{i j}\right]$ and is denoted by $\left[a_{i j}\right]^{\tilde{c}}$ or $\left[a_{i j}^{\tilde{c}}\right]$. 
Definition 2.8. $[13,40]$ Let $\left[a_{i j}\right],\left[b_{i j}\right] \in \operatorname{FPFS}_{E}[U]$. If $\left[a_{i j}\right] \widetilde{\cap}\left[b_{i j}\right]=[0]$, then $\left[a_{i j}\right]$ and $\left[b_{i j}\right]$ are called disjoint.

Definition 2.9. [40] Let $\left[a_{i j}\right]_{m \times n_{1}} \in F P F S_{E_{1}}[U], \quad\left[b_{i k}\right]_{m \times n_{2}} \in F P F S_{E_{2}}[U]$, and $\left[c_{i p}\right]_{m \times n_{1} n_{2}} \in$ $F P F S_{E_{1} \times E_{2}}[U]$ such that $p=n_{2}(j-1)+k$. For all $i$ and $p$,

If $c_{i p}:=\min \left\{a_{i j}, b_{i k}\right\}$, then $\left[c_{i p}\right]$ is called and-product of $\left[a_{i j}\right]$ and $\left[b_{i k}\right]$ and is denoted by $\left[a_{i j}\right] \wedge\left[b_{i k}\right]$,

If $c_{i p}:=\max \left\{a_{i j}, b_{i k}\right\}$, then $\left[c_{i p}\right]$ is called or-product of $\left[a_{i j}\right]$ and $\left[b_{i k}\right]$ and is denoted by $\left[a_{i j}\right] \vee$ $\left[b_{i k}\right]$,

If $c_{i p}:=\min \left\{a_{i j}, 1-b_{i k}\right\}$, then $\left[c_{i p}\right]$ is called andnot-product of $\left[a_{i j}\right]$ and $\left[b_{i k}\right]$ and is denoted by $\left[a_{i j}\right] \bar{\wedge}\left[b_{i k}\right]$,

If $c_{i p}:=\max \left\{a_{i j}, 1-b_{i k}\right\}$, then $\left[c_{i p}\right]$ is called ornot-product of $\left[a_{i j}\right]$ and $\left[b_{i k}\right]$ and is denoted by $\left[a_{i j}\right] \underline{\mathrm{v}}\left[b_{i k}\right]$.

Secondly, we present the algorithm CE12 [5,12,34].

Step 1. Construct two $f p f s$-matrices $\left[a_{i j}\right]$ and $\left[b_{i k}\right]$

Step 2. Find and-product/or-product $f p f s$-matrix $\left[c_{i p}\right]$ of $\left[a_{i j}\right]$ and $\left[b_{i k}\right]$

Step 3. Obtain $\left[s_{i 1}\right]$ defined by

$$
s_{i 1}:=\max _{k}\left\{\begin{array}{cc}
\min _{p \in I_{k}}\left\{c_{0 p} c_{i p}\right\}, & I_{k} \neq \varnothing \\
0, & I_{k}=\varnothing
\end{array}\right.
$$

such that $i \in\{1,2, \ldots, m-1\}$ and $I_{k}:=\left\{p \mid \exists i, c_{0 p} c_{i p} \neq 0,(k-1) n<p \leq k n\right\}$

Step 4. Obtain the set $\left\{u_{k} \mid s_{k 1}=\max _{i}\left(s_{i 1}\right)\right\}$

Preferably, the set $\left\{{ }^{s_{i 1}} u_{i} \mid u_{i} \in U\right\}$ or $\left\{{ }^{\mu\left(u_{k}\right)} u_{k} \mid u_{k} \in U\right\}$ can be attained such that $\mu\left(u_{k}\right)=\frac{s_{k 1}}{\max _{i} s_{i 1}}$.

\section{Soft Decision-Making Methods: EMC19a and EMC19o}

In this section, we first propose an algorithm denoted by EMC19a.

Step 1. Construct two $f p f s$-matrices $\left[a_{i j}\right]$ and $\left[b_{i k}\right]$

Step 2. Obtain score matrix $\left[s_{i 1}\right]$ defined by

$$
s_{i 1}:=\left\{\begin{array}{cc}
\min \left\{\max _{j \in I_{a}}\left\{a_{0 j} a_{i j}\right\}, \min _{k \in I_{b}}\left\{b_{0 k} b_{i k}\right\}\right\}, & I_{a} \neq \varnothing \text { and } I_{b} \neq \varnothing \\
0, & \text { otherwise }
\end{array}\right.
$$

such that $i \in\{1,2, \ldots, m-1\}, I_{a}:=\left\{j \mid \exists i, a_{0 j} a_{i j} \neq 0\right\}$, and $I_{b}:=\left\{k \mid \exists i, b_{0 k} b_{i k} \neq 0\right\}$

Step 3. Obtain the decision set $\left\{{ }^{s_{i 1}} u_{i} \mid u_{i} \in U\right\}$

It is clear that the values $s_{i 1}$ give a ranking order over $u_{i}$. Therefore, the decision maker can choose the proper ones of the alternatives.

Theorem 4.1. EMC19a is equivalent to CE12a under the condition that first rows of the fpfsmatrices are binary.

PROOF. Let us consider the functions $s_{i 1}$ provided in CE12a and EMC19a, and show $I_{k} \neq \emptyset \Leftrightarrow$ $\left(I_{a} \neq \emptyset \wedge I_{b} \neq \varnothing\right)$. Then,

$$
\begin{aligned}
I_{k} \neq \varnothing & \Leftrightarrow \exists i, c_{0 p} c_{i p} \neq 0 \\
& \Leftrightarrow \exists i,\left(c_{0 p} \neq 0 \wedge c_{i p} \neq 0\right)
\end{aligned}
$$




$$
\begin{aligned}
& \Leftrightarrow \exists i,\left(\min \left\{a_{0 j}, b_{0 k}\right\} \neq 0 \wedge \min \left\{a_{i j}, b_{i k}\right\} \neq 0\right) \\
& \Leftrightarrow \exists i,\left(a_{0 j} \neq 0 \wedge b_{0 k} \neq 0 \wedge a_{i j} \neq 0 \wedge b_{i k} \neq 0\right) \\
& \Leftrightarrow \exists i,\left(a_{0 j} a_{i j} \neq 0 \wedge b_{0 k} b_{i k} \neq 0\right) \\
& \Leftrightarrow I_{a} \neq \emptyset \wedge I_{b} \neq \varnothing
\end{aligned}
$$

In a similar way,

$$
\begin{aligned}
I_{k}=\emptyset & \Leftrightarrow \forall i, c_{0 p} c_{i p}=0 \\
& \Leftrightarrow \forall i,\left(c_{0 p}=0 \vee c_{i p}=0\right) \\
& \Leftrightarrow \forall i,\left(\min \left\{a_{0 j}, b_{0 k}\right\}=0 \vee \min \left\{a_{i j}, b_{i k}\right\}=0\right) \\
& \Leftrightarrow \forall i,\left(a_{0 j}=0 \vee b_{0 k}=0 \vee a_{i j}=0 \vee b_{i k}=0\right) \\
& \Leftrightarrow \forall i,\left(a_{0 j} a_{i j}=0 \vee b_{0 k} b_{i k}=0\right) \\
& \Leftrightarrow I_{a}=\emptyset \vee I_{b}=\emptyset
\end{aligned}
$$

Here, $i \in\{1,2, \ldots, m-1\}, j, k \in\{1,2, \ldots, n\}, p=n(j-1)+k$, and $(k-1) n<p \leq k n$.

Suppose that first rows of the $f p f s$-matrices are binary, $I_{k}=\left\{t_{1}^{k}, t_{2}^{k}, \ldots, t_{r(k)}^{k}\right\}, I_{a}=\left\{a_{1}, a_{2}, \ldots, a_{s}\right\}$, and $I_{b}=\left\{b_{1}, b_{2}, \ldots, b_{t}\right\}$. The functions $s_{i 1}$ provided in CE12a and EMC19a are equal in the event that $I_{a}=\varnothing$ or $I_{b}=\varnothing$. Assume that $I_{a} \neq \varnothing$ and $I_{b} \neq \varnothing$. Since $a_{0 j}=1$ and $b_{0 k}=1$, for all $j \in I_{a}$ and $k \in I_{b}$,

$$
\begin{aligned}
& \max _{k}\left\{\min _{p \in I_{k}}\left(c_{0 p} c_{i p}\right)\right\}=\max \left\{\min \left\{c_{0 t_{1}^{1}} c_{i t_{1}^{1}}, c_{0 t_{2}^{1}} c_{i t_{2}^{1}}, \ldots, c_{0 t_{r(1)}^{1}} c_{i t_{r(1)}^{1}}\right\},\right. \\
& \min \left\{c_{0 t_{1}^{2}} c_{i t_{1}^{2}}, c_{0 t_{2}^{2}} c_{i t_{2}^{2}}, \ldots, c_{0 t_{r(2)}^{2}} c_{i t_{r(2)}^{2}}\right\}, \ldots, \\
& \left.\min \left\{c_{0 t_{1}^{k}} c_{i t_{1}^{k}}, c_{0 t_{2}^{k}} c_{i t_{2}^{k}}, \ldots, c_{0 t_{r(k)}^{k}} c_{i t_{r(k)}^{k}}\right\}\right\} \\
& =\max \left\{\min \left\{c_{i t_{1}^{1}}, c_{i t_{2}^{1}}, \ldots, c_{i t_{r(1)}^{1}}\right\}\right. \text {, } \\
& \min \left\{c_{i t_{1}^{2}}, c_{i t_{2}^{2}}, \ldots, c_{i t_{r(2)}^{2}}\right\}, \ldots, \\
& \left.\min \left\{c_{i t_{1}^{k}}, c_{i t_{2}^{k}}, \ldots, c_{i t_{r(k)}^{k}}\right\}\right\} \\
& =\max \left\{\min \left\{\min \left\{a_{i a_{1}}, b_{i b_{1}}\right\}, \min \left\{a_{i a_{1}}, b_{i b_{2}}\right\}, \ldots, \min \left\{a_{i a_{1}}, b_{i b_{t}}\right\}\right\}\right. \text {, } \\
& \min \left\{\min \left\{a_{i a_{2}}, b_{i b_{1}}\right\}, \min \left\{a_{i a_{2}}, b_{i b_{2}}\right\}, \ldots, \min \left\{a_{i a_{2}}, b_{i b_{t}}\right\}\right\}, \ldots, \\
& \left.\min \left\{\min \left\{a_{i a_{s}}, b_{i b_{1}}\right\}, \min \left\{a_{i a_{s}}, b_{i b_{2}}\right\}, \ldots, \min \left\{a_{i a_{s}}, b_{i b_{t}}\right\}\right\}\right\} \\
& =\max \left\{\min \left\{a_{i a_{1}}, \min \left\{b_{i b_{1}}, b_{i b_{2}}, \ldots, b_{i b_{t}}\right\}\right\}\right. \text {, } \\
& \min \left\{a_{i a_{2}}, \min \left\{b_{i b_{1}}, b_{i b_{2}}, \ldots, b_{i b_{t}}\right\}\right\}, \ldots, \\
& \left.\min \left\{a_{i a_{s}}, \min \left\{b_{i b_{1}}, b_{i b_{2}}, \ldots, b_{i b_{t}}\right\}\right\}\right\} \\
& =\min \left\{\max \left\{a_{i a_{1}}, a_{i a_{2}}, \ldots, a_{i a_{s}}\right\}, \min \left\{b_{i b_{1}}, b_{i b_{2}}, \ldots, b_{i b_{t}}\right\}\right\} \\
& =\min \left\{\max _{j \in I_{a}} a_{i j}, \min _{k \in I_{b}} b_{i k}\right\}
\end{aligned}
$$




$$
=\min \left\{\max _{j \in I_{a}}\left\{a_{0 j} a_{i j}\right\}, \min _{k \in I_{b}}\left\{b_{0 k} b_{i k}\right\}\right\}
$$

Secondly, we propose another algorithm denoted by EMC19o.

Step 1. Construct two $f p f s$-matrices $\left[a_{i j}\right]$ and $\left[b_{i k}\right]$

Step 2. Obtain score matrix $\left[s_{i 1}\right]$ defined by

$$
s_{i 1}:=\left\{\begin{array}{cc}
\max \left\{\max _{j \in I_{a}}\left\{a_{0 j} a_{i j}\right\}, \min _{k \in I_{b}}\left\{b_{0 k} b_{i k}\right\}\right\}, & I_{a} \neq \varnothing \text { and } I_{b} \neq \varnothing \\
0, & \text { otherwise }
\end{array}\right.
$$

such that $i \in\{1,2, \ldots, m-1\}, I_{a}:=\left\{j \mid \exists i, a_{0 j} a_{i j} \neq 0\right\}$, and $I_{b}:=\left\{k \mid \exists i, b_{0 k} b_{i k} \neq 0\right\}$

Step 3. Obtain the decision set $\left\{{ }^{s_{i 1}} u_{i} \mid u_{i} \in U\right\}$

It is clear that the values $s_{i 1}$ give a ranking order over $u_{i}$. Therefore, the decision maker can choose the proper ones of the alternatives.

\section{Simulation Results}

In this section, we first compare the running times of CE12a and EMC19a by using MATLAB R2018b. So long as it has not been encountered a difficulty, we use a laptop with $2.6 \mathrm{GHz}$ i5 Dual Core CPU and 4 GB RAM to compare the methods. However, in this study, we use a workstation with I(R) Xeon(R) CPU E5-1620 v4@ @ 3.5 GHz and 64 GB RAM because the computer is insufficient to run CE12a if the parameters are more than 5000.

We present the running times of CE12a and EMC19a in Table 1 and Fig. 1 for 10 objects and the parameters ranging from 10 to 100 . Even though the difference of running times between these methods is low, EMC19a is about 70 times faster than CE12a in 100 parameters and 10 objects.

Table 1. The running times of the methods for 10 objects and 10-100 parameters (In Second)

\begin{tabular}{lcccccccccc}
\hline \hline Parameter Count & $\mathbf{1 0}$ & $\mathbf{2 0}$ & $\mathbf{3 0}$ & $\mathbf{4 0}$ & $\mathbf{5 0}$ & $\mathbf{6 0}$ & $\mathbf{7 0}$ & $\mathbf{8 0}$ & $\mathbf{9 0}$ & $\mathbf{1 0 0}$ \\
\hline \hline CE12a & 0.01811 & 0.00548 & 0.00166 & 0.00273 & 0.00604 & 0.00780 & 0.00941 & 0.00839 & 0.01225 & 0.01640 \\
EMC19a & 0.00789 & 0.00237 & 0.00039 & 0.00038 & 0.00211 & 0.00081 & 0.00042 & 0.00019 & 0.00032 & 0.00024 \\
Difference & 0.0102 & 0.0031 & 0.0013 & 0.0024 & 0.0039 & 0.0070 & 0.0090 & 0.0082 & 0.0119 & 0.0162 \\
Advantage (\%) & 56.4254 & 56.6633 & 76.2652 & 86.2857 & 65.0508 & 89.6560 & 95.5149 & 97.7886 & 97.4096 & 98.5428 \\
\hline \hline
\end{tabular}

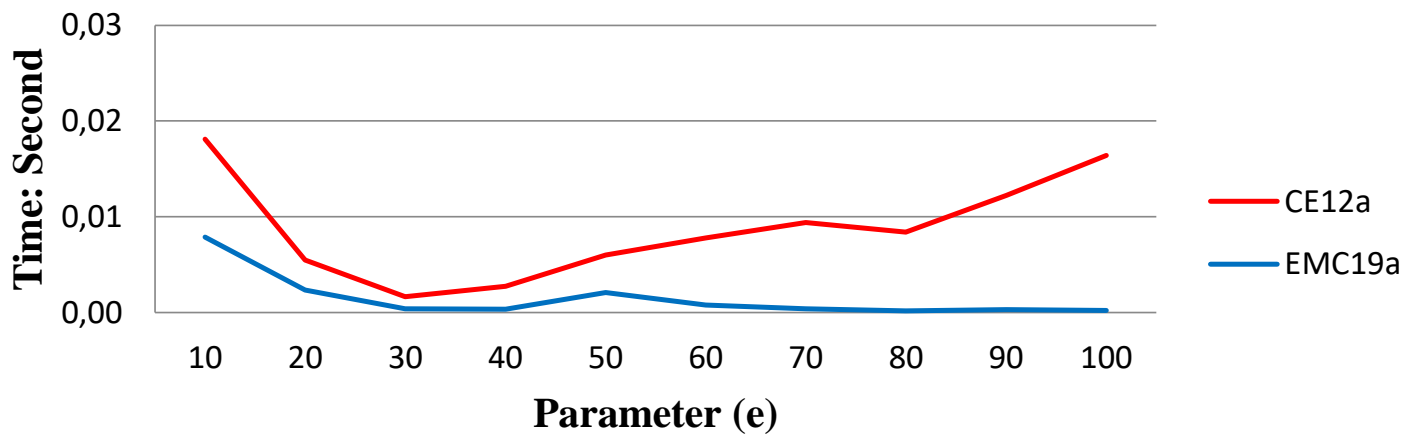

Figure 1. The figure for Table 1 
We then give the running times of CE12a and EMC19a in Table 2 and Fig. 2 for 10 objects and the parameters ranging from 1000 to 10000 . It must be noted that the difference in running times between these methods is increasing seriously. 278-second running time shows CE12a is not appropriate for any real-time software processing a large amount of data.

Table 2. The running times of the methods for 10 objects and 1000-10000 parameters (In Second)

\begin{tabular}{lcccccccccc}
\hline Parameter Count & $\mathbf{1 0 0 0}$ & $\mathbf{2 0 0 0}$ & $\mathbf{3 0 0 0}$ & $\mathbf{4 0 0 0}$ & $\mathbf{5 0 0 0}$ & $\mathbf{6 0 0 0}$ & $\mathbf{7 0 0 0}$ & $\mathbf{8 0 0 0}$ & $\mathbf{9 0 0 0}$ & $\mathbf{1 0 0 0 0}$ \\
\hline CE12a & 0.7436 & 3.3679 & 9.9886 & 22.4843 & 40.8677 & 66.2469 & 102.8899 & 147.6173 & 202.8367 & 278.8861 \\
EMC19a & 0.0080 & 0.0027 & 0.0013 & 0.0015 & 0.0034 & 0.0026 & 0.0019 & 0.0024 & 0.0041 & 0.0026 \\
Difference & 0.7356 & 3.3652 & 9.9873 & 22.4828 & 40.8642 & 66.2443 & 102.8880 & 147.6149 & 202.8326 & 278.8835 \\
Advantage (\%) & 98.9276 & 99.9201 & 99.9867 & 99.9933 & 99.9916 & 99.9960 & 99.9981 & 99.9984 & 99.9980 & 99.9991 \\
\hline
\end{tabular}

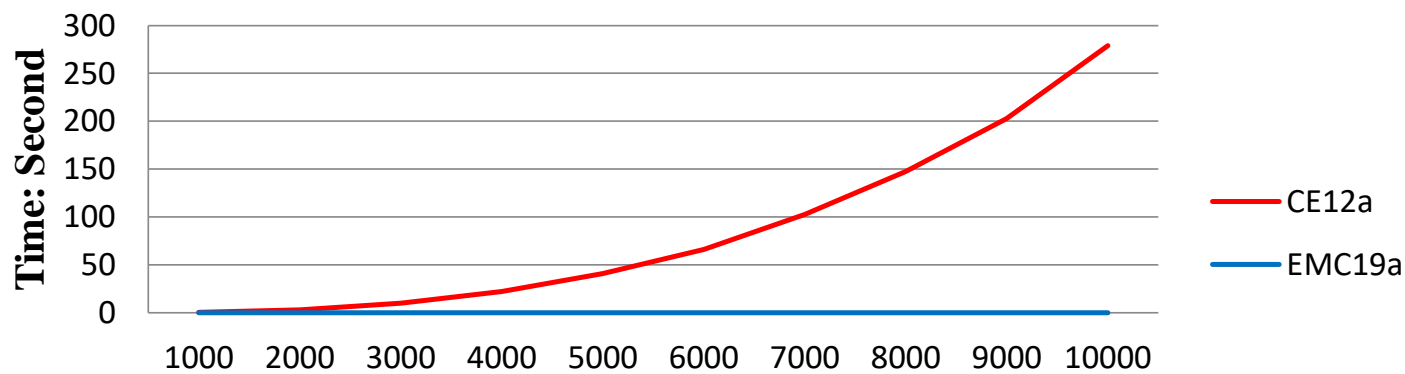

Parameter (e)

Figure 2. The figure for Table 2

We then give their running times in Table 3 and Fig. 3 for 10 parameters and the objects ranging from 10 to 100. Despite the low difference of running times between these methods, EMC19a is about 5 times faster than CE12a in 10 parameters and 100 objects.

Table 3. The running times of the methods for 10-100 objects and 10 parameters (In Second)

\begin{tabular}{lcccccccccc}
\hline Object Count & $\mathbf{1 0}$ & $\mathbf{2 0}$ & $\mathbf{3 0}$ & $\mathbf{4 0}$ & $\mathbf{5 0}$ & $\mathbf{6 0}$ & $\mathbf{7 0}$ & $\mathbf{8 0}$ & $\mathbf{9 0}$ & $\mathbf{1 0 0}$ \\
\hline CE12a & 0.0141 & 0.0047 & 0.0022 & 0.0014 & 0.0032 & 0.0037 & 0.0041 & 0.0054 & 0.0033 & 0.0024 \\
EMC19a & 0.0074 & 0.0020 & 0.0005 & 0.0003 & 0.0017 & 0.0011 & 0.0009 & 0.0008 & 0.0005 & 0.0005 \\
Difference & 0.0067 & 0.0027 & 0.0017 & 0.0011 & 0.0015 & 0.0026 & 0.0032 & 0.0046 & 0.0028 & 0.0019 \\
Advantage (\%) & 47.2867 & 58.0965 & 77.5393 & 78.0378 & 47.8422 & 71.2486 & 78.3838 & 85.0085 & 84.7237 & 78.6004 \\
\hline
\end{tabular}

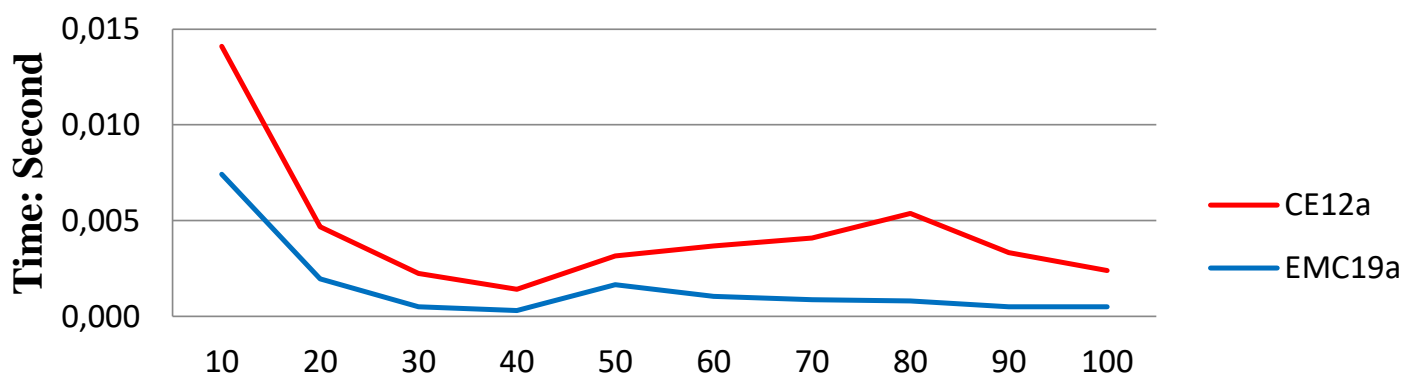

Object (u)

Figure 3. The figure for Table 3 
We then give their running times in Table 4 and Fig. 4 for 10 parameters and the objects ranging from 1000 to 10000 . The results show that only increasing the objects do not affect the running time as much as only increasing the parameters. Besides, in a large number of parameters, EMC19a works faster than in a large number of objects.

Table 4. The running times of the methods for 1000-10000 objects and 10 parameters (In Second)

\begin{tabular}{lcccccccccc}
\hline Object Count & $\mathbf{1 0 0 0}$ & $\mathbf{2 0 0 0}$ & $\mathbf{3 0 0 0}$ & $\mathbf{4 0 0 0}$ & $\mathbf{5 0 0 0}$ & $\mathbf{6 0 0 0}$ & $\mathbf{7 0 0 0}$ & $\mathbf{8 0 0 0}$ & $\mathbf{9 0 0 0}$ & $\mathbf{1 0 0 0 0}$ \\
\hline CE12a & 0.0602 & 0.1216 & 0.2389 & 0.3778 & 0.5634 & 0.7539 & 1.0909 & 1.3661 & 1.6618 & 1.9791 \\
EMC19a & 0.0116 & 0.0129 & 0.0175 & 0.0242 & 0.0342 & 0.0414 & 0.0492 & 0.0590 & 0.0687 & 0.0812 \\
Difference & 0.0486 & 0.1087 & 0.2214 & 0.3536 & 0.5292 & 0.7125 & 1.0417 & 1.3071 & 1.5931 & 1.8979 \\
Advantage (\%) & 80.7231 & 89.3771 & 92.6951 & 93.5828 & 93.9242 & 94.5032 & 95.4878 & 95.6795 & 95.8664 & 95.8986 \\
\hline
\end{tabular}

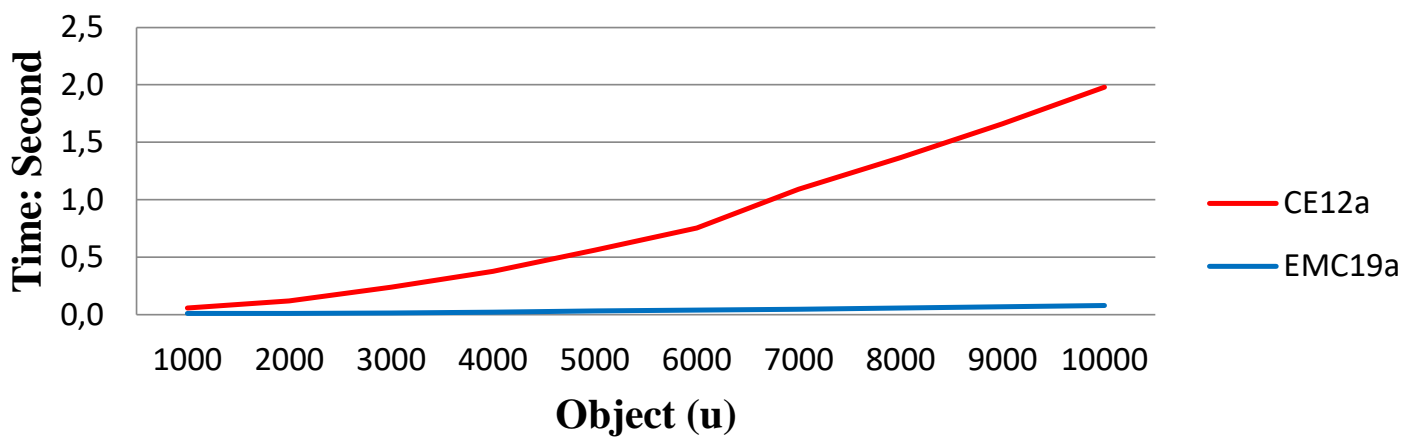

Figure 4. The figure for Table 4

We then give their running times in Table 5 and Fig. 5 for the parameters and the objects ranging from 10 to 100. Although the difference of running times between these methods is low, EMC19a is up to 130 times faster than CE12a.

Table 5. The running times of the methods for 10-100 objects and parameters (In Second)

\begin{tabular}{lcccccccccc}
\hline Count & $\mathbf{1 0}$ & $\mathbf{2 0}$ & $\mathbf{3 0}$ & $\mathbf{4 0}$ & $\mathbf{5 0}$ & $\mathbf{6 0}$ & $\mathbf{7 0}$ & $\mathbf{8 0}$ & $\mathbf{9 0}$ & $\mathbf{1 0 0}$ \\
\hline CE12a & 0.0140 & 0.0055 & 0.0044 & 0.0076 & 0.0151 & 0.0233 & 0.0349 & 0.0447 & 0.0653 & 0.0905 \\
EMC19a & 0.0057 & 0.0017 & 0.0009 & 0.0006 & 0.0022 & 0.0011 & 0.0006 & 0.0006 & 0.0007 & 0.0007 \\
Difference & 0.0083 & 0.0037 & 0.0035 & 0.0070 & 0.0129 & 0.0222 & 0.0343 & 0.0441 & 0.0647 & 0.0897 \\
Advantage (\%) & 59.2037 & 68.2321 & 80.3370 & 92.0232 & 85.3565 & 95.0726 & 98.2459 & 98.5621 & 98.9913 & 99.2141 \\
\hline
\end{tabular}

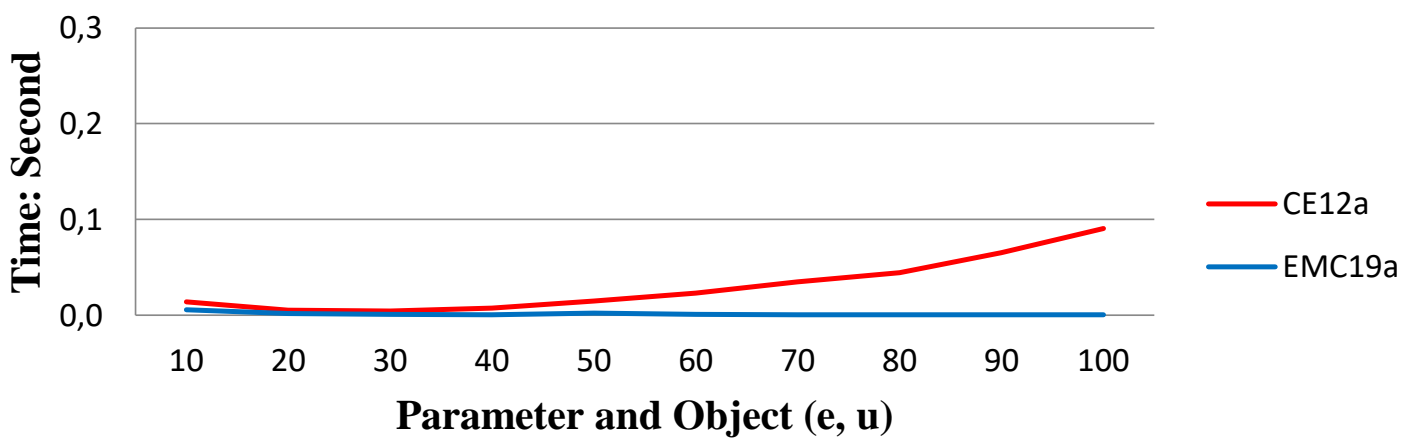

Figure 5. The figure for Table 5

We then give their running times in Table 6 and Fig. 6 for the parameters and the objects ranging from 100 to 1000. 0.0206-second and 616-second running times shows EMC19a is more appropriate than CE12a for any real-time software. 
Table 6. The running times of the methods for 100-1000 objects and parameters (In Second)

\begin{tabular}{lcccccccccc}
\hline Count & $\mathbf{1 0 0}$ & $\mathbf{2 0 0}$ & $\mathbf{3 0 0}$ & $\mathbf{4 0 0}$ & $\mathbf{5 0 0}$ & $\mathbf{6 0 0}$ & $\mathbf{7 0 0}$ & $\mathbf{8 0 0}$ & $\mathbf{9 0 0}$ & $\mathbf{1 0 0 0}$ \\
\hline CE12a & 0.1447 & 1.3295 & 5.9489 & 17.0769 & 39.5983 & 79.2793 & 145.0186 & 244.9221 & 399.8934 & 616.6867 \\
EMC19a & 0.0101 & 0.0036 & 0.0038 & 0.0048 & 0.0083 & 0.0091 & 0.0114 & 0.0134 & 0.0172 & 0.0206 \\
Difference & 0.1346 & 1.3258 & 5.9451 & 17.0721 & 39.5900 & 79.2702 & 145.0072 & 244.9088 & 399.8762 & 616.6662 \\
Advantage (\%) & 92.9952 & 99.7266 & 99.9355 & 99.9720 & 99.9791 & 99.9885 & 99.9921 & 99.9945 & 99.9957 & 99.9967 \\
\hline
\end{tabular}

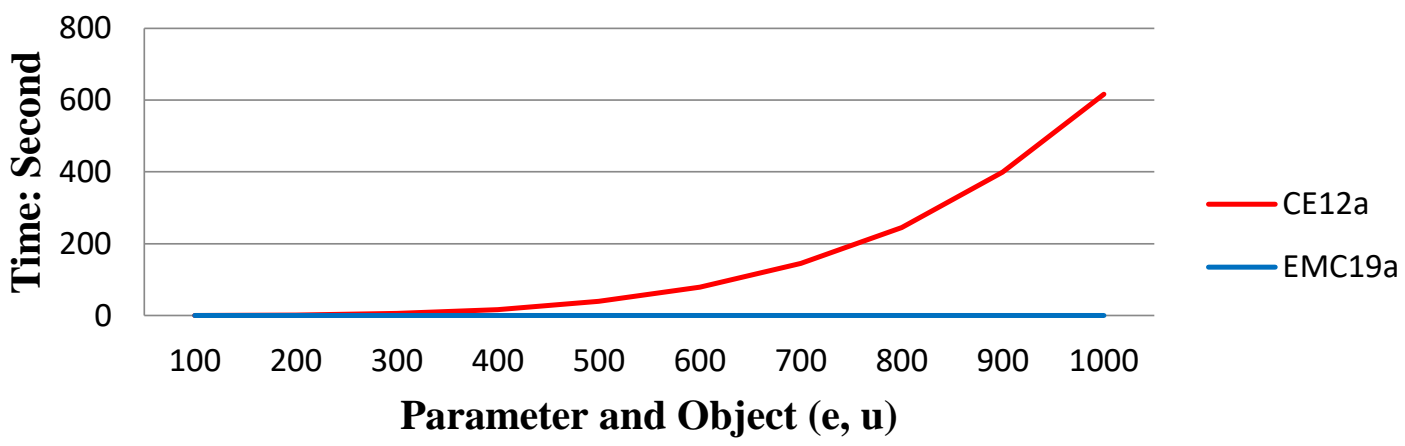

Figure 6. The figure for Table 6. The results show that EMC19a outperforms than CE12a in any number of data.

Secondly, we compare the running times of CE12o and EMC19o by using MATLAB R2018b and a workstation with I(R) Xeon(R) CPU E5-1620 v4 @ $3.5 \mathrm{GHz}$ and 64 GB RAM because the computer mentioned above is insufficient to run CE12o if the parameters are more than 5000.

We present the running times of CE12o and EMC19o in Table 7 and Fig. 7 for 10 objects and the parameters ranging from 10 to 100. Even though the difference of running times between these methods is low, EMC19o is about 100 times faster than CE12o in 100 parameters and 10 objects.

Table 7. The running times of the methods for 10 objects and 10-100 parameters (In Second)

\begin{tabular}{lccccccccccc}
\hline Parameter Count & $\mathbf{1 0}$ & $\mathbf{2 0}$ & $\mathbf{3 0}$ & $\mathbf{4 0}$ & $\mathbf{5 0}$ & $\mathbf{6 0}$ & $\mathbf{7 0}$ & $\mathbf{8 0}$ & $\mathbf{9 0}$ & $\mathbf{1 0 0}$ \\
\hline CE120 & 0.0117 & 0.0054 & 0.0023 & 0.0030 & 0.0085 & 0.0086 & 0.0112 & 0.0143 & 0.0162 & 0.0203 \\
EMC19o & 0.0066 & 0.0024 & 0.0004 & 0.0003 & 0.0025 & 0.0005 & 0.0001 & 0.0002 & 0.0002 & 0.0002 \\
Difference & 0.0052 & 0.0030 & 0.0019 & 0.0026 & 0.0061 & 0.0081 & 0.0111 & 0.0140 & 0.0159 & 0.0200 \\
Advantage (\%) & 43.9452 & 55.0417 & 82.2197 & 88.7153 & 70.9732 & 94.4846 & 98.7038 & 98.4619 & 98.6299 & 98.8234 \\
\hline
\end{tabular}

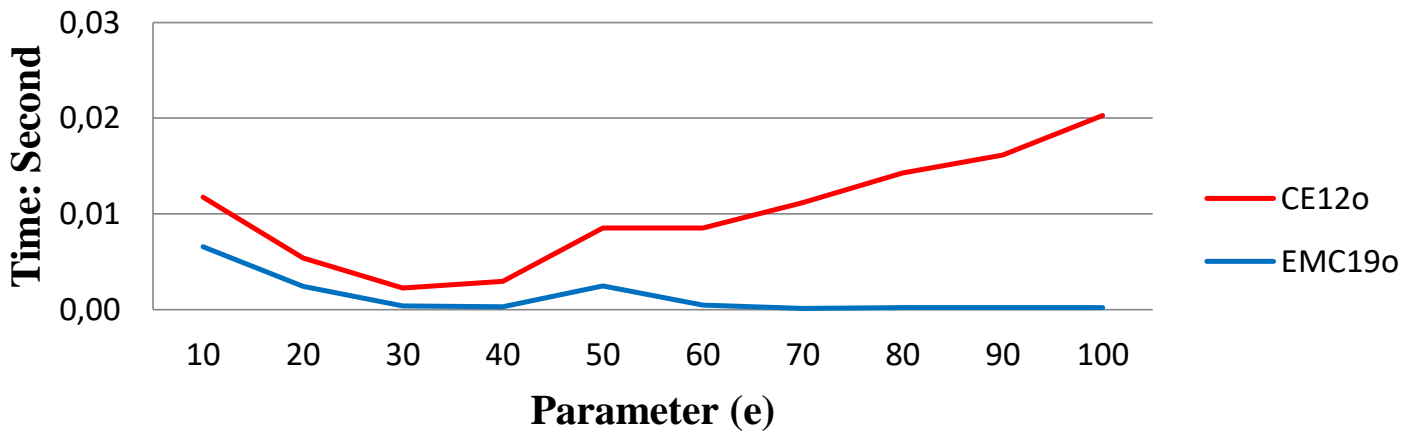

Figure 7. The figure for Table 7

We then give the running times of CE12o and EMC19o in Table 8 and Fig. 8 for 10 objects and the parameters ranging from 1000 to 10000 . It must be noted that the difference in running times between these methods is increasing seriously. 515-second running time shows CE12o is not appropriate for any real-time software processing a large amount of data. 
Table 8. The running times of the methods for 10 objects and 1000-10000 parameters (In Second)

\begin{tabular}{lcccccccccc}
\hline Parameter Count & $\mathbf{1 0 0 0}$ & $\mathbf{2 0 0 0}$ & $\mathbf{3 0 0 0}$ & $\mathbf{4 0 0 0}$ & $\mathbf{5 0 0 0}$ & $\mathbf{6 0 0 0}$ & $\mathbf{7 0 0 0}$ & $\mathbf{8 0 0 0}$ & $\mathbf{9 0 0 0}$ & $\mathbf{1 0 0 0 0}$ \\
\hline CE120 & 0.8761 & 6.0139 & 18.1107 & 39.1060 & 72.1961 & 117.6709 & 184.9469 & 271.8735 & 373.6522 & 515.0063 \\
EMC190 & 0.0074 & 0.0028 & 0.0014 & 0.0016 & 0.0034 & 0.0027 & 0.0020 & 0.0023 & 0.0025 & 0.0027 \\
Difference & 0.8687 & 6.0111 & 18.1093 & 39.1044 & 72.1927 & 117.6682 & 184.9449 & 271.8712 & 373.6497 & 515.0036 \\
Advantage (\%) & 99.1569 & 99.9539 & 99.9923 & 99.9959 & 99.9952 & 99.9977 & 99.9989 & 99.9991 & 99.9993 & 99.9995 \\
\hline
\end{tabular}

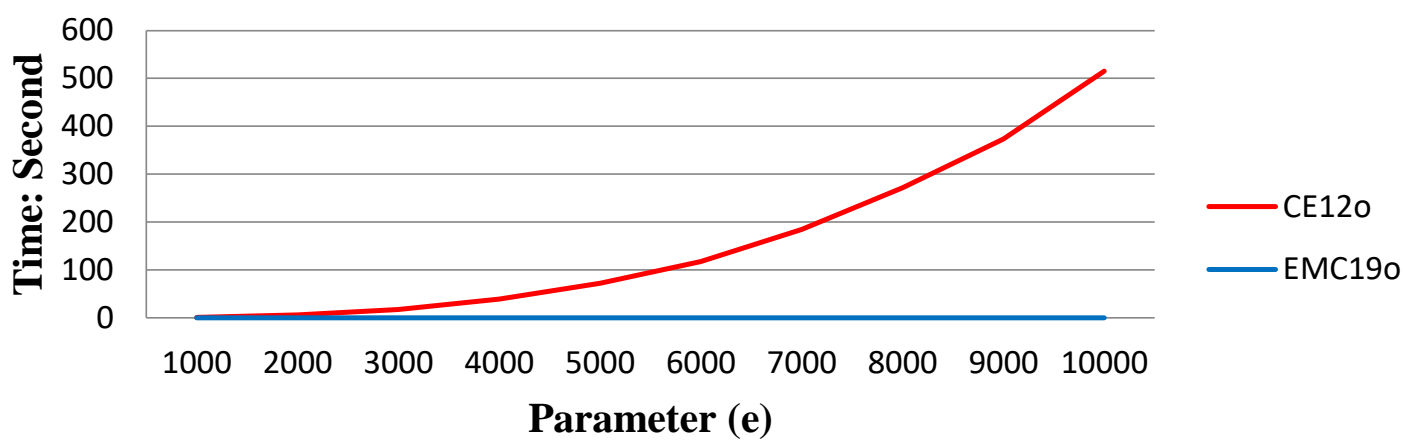

Figure 8. The figure for Table 8

We then give their running times in Table 9 and Fig. 9 for 10 parameters and the objects ranging from 10 to 100. Despite the low difference of running times between these methods, EMC19o is about 7 times faster than CE12o in 10 parameters and 100 objects.

Table 9. The running times of the methods for 10-100 objects and 10 parameters (In Second)

\begin{tabular}{lcccccccccc}
\hline Object Count & $\mathbf{1 0}$ & $\mathbf{2 0}$ & $\mathbf{3 0}$ & $\mathbf{4 0}$ & $\mathbf{5 0}$ & $\mathbf{6 0}$ & $\mathbf{7 0}$ & $\mathbf{8 0}$ & $\mathbf{9 0}$ & $\mathbf{1 0 0}$ \\
\hline CE120 & 0.0113 & 0.0044 & 0.0017 & 0.0018 & 0.0039 & 0.0053 & 0.0056 & 0.0062 & 0.0038 & 0.0043 \\
EMC190 & 0.0058 & 0.0020 & 0.0004 & 0.0003 & 0.0016 & 0.0019 & 0.0008 & 0.0006 & 0.0005 & 0.0006 \\
Difference & 0.0056 & 0.0025 & 0.0013 & 0.0015 & 0.0023 & 0.0034 & 0.0048 & 0.0056 & 0.0033 & 0.0038 \\
Advantage (\%) & 49.2078 & 55.1922 & 73.7450 & 82.3905 & 57.8698 & 63.7274 & 84.9306 & 90.7323 & 86.8001 & 87.2092 \\
\hline
\end{tabular}

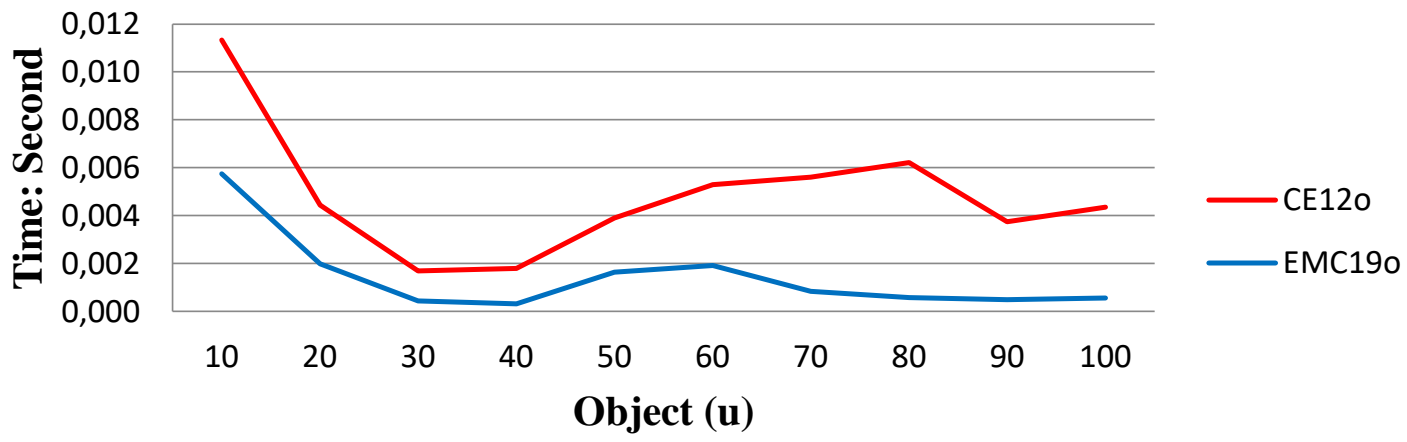

Figure 9. The figure for Table 9

We then give their running times in Table 10 and Fig. 10 for 10 parameters and the objects ranging from 1000 to 10000 . The results show that only increasing the objects do not affect the running time as much as only increasing the parameters. Besides, in a large number of parameters, EMC19o works faster than in a large number of objects. 
Table 10. The running times of the methods for 1000-10000 objects and 10 parameters (In Second)

\begin{tabular}{lcccccccccc}
\hline Object Count & $\mathbf{1 0 0 0}$ & $\mathbf{2 0 0 0}$ & $\mathbf{3 0 0 0}$ & $\mathbf{4 0 0 0}$ & $\mathbf{5 0 0 0}$ & $\mathbf{6 0 0 0}$ & $\mathbf{7 0 0 0}$ & $\mathbf{8 0 0 0}$ & $\mathbf{9 0 0 0}$ & $\mathbf{1 0 0 0 0}$ \\
\hline CE120 & 0.0761 & 0.1539 & 0.2690 & 0.4271 & 0.6235 & 0.8606 & 1.1178 & 1.4193 & 1.7636 & 2.1721 \\
EMC190 & 0.0116 & 0.0135 & 0.0172 & 0.0263 & 0.0338 & 0.0413 & 0.0497 & 0.0598 & 0.0691 & 0.0816 \\
Difference & 0.0645 & 0.1404 & 0.2518 & 0.4008 & 0.5898 & 0.8193 & 1.0682 & 1.3594 & 1.6945 & 2.0905 \\
Advantage (\%) & 84.7582 & 91.2375 & 93.5980 & 93.8512 & 94.5847 & 95.1976 & 95.5574 & 95.7834 & 96.0829 & 96.2443 \\
\hline
\end{tabular}

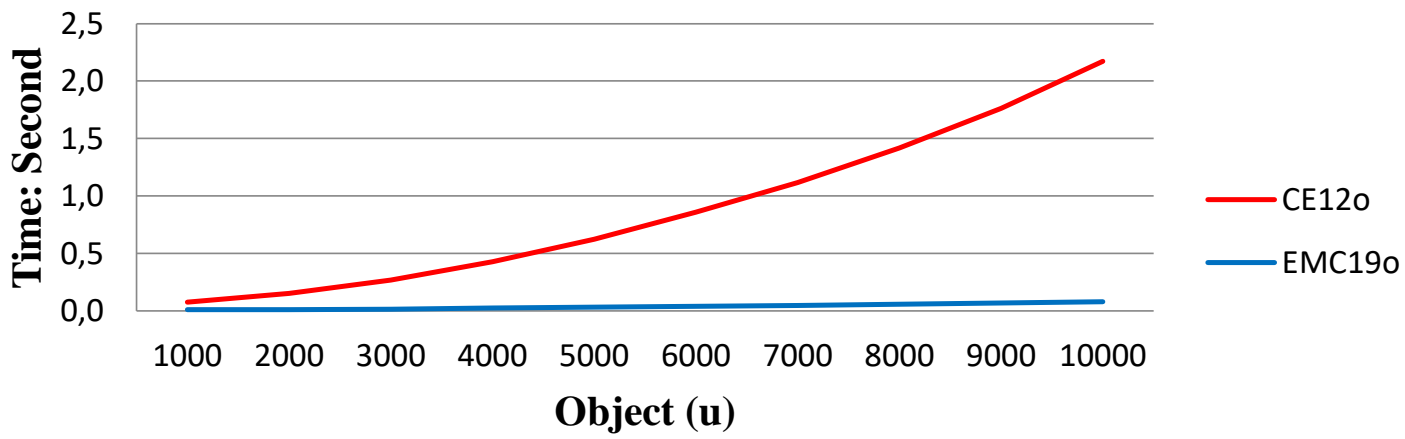

Figure 10. The figure for Table 10

We then give their running times in Table 11 and Fig. 11 for the parameters and the objects ranging from 10 to 100. Although the difference of running times between these methods is low, EMC19o is up to 150 times faster than CE12o.

Table 11. The running times of the methods for 10-100 objects and parameters (In Second)

\begin{tabular}{lcccccccccc}
\hline Count & $\mathbf{1 0}$ & $\mathbf{2 0}$ & $\mathbf{3 0}$ & $\mathbf{4 0}$ & $\mathbf{5 0}$ & $\mathbf{6 0}$ & $\mathbf{7 0}$ & $\mathbf{8 0}$ & $\mathbf{9 0}$ & $\mathbf{1 0 0}$ \\
\hline CE120 & 0.0106 & 0.0059 & 0.0050 & 0.0103 & 0.0197 & 0.0353 & 0.0447 & 0.0685 & 0.0829 & 0.1030 \\
EMC190 & 0.0053 & 0.0018 & 0.0009 & 0.0006 & 0.0022 & 0.0012 & 0.0006 & 0.0006 & 0.0007 & 0.0007 \\
Difference & 0.0053 & 0.0041 & 0.0041 & 0.0097 & 0.0175 & 0.0341 & 0.0441 & 0.0679 & 0.0822 & 0.1023 \\
Advantage (\%) & 50.0941 & 69.9820 & 82.4312 & 93.8611 & 88.6337 & 96.5521 & 98.5871 & 99.1218 & 99.1953 & 99.3082 \\
\hline
\end{tabular}

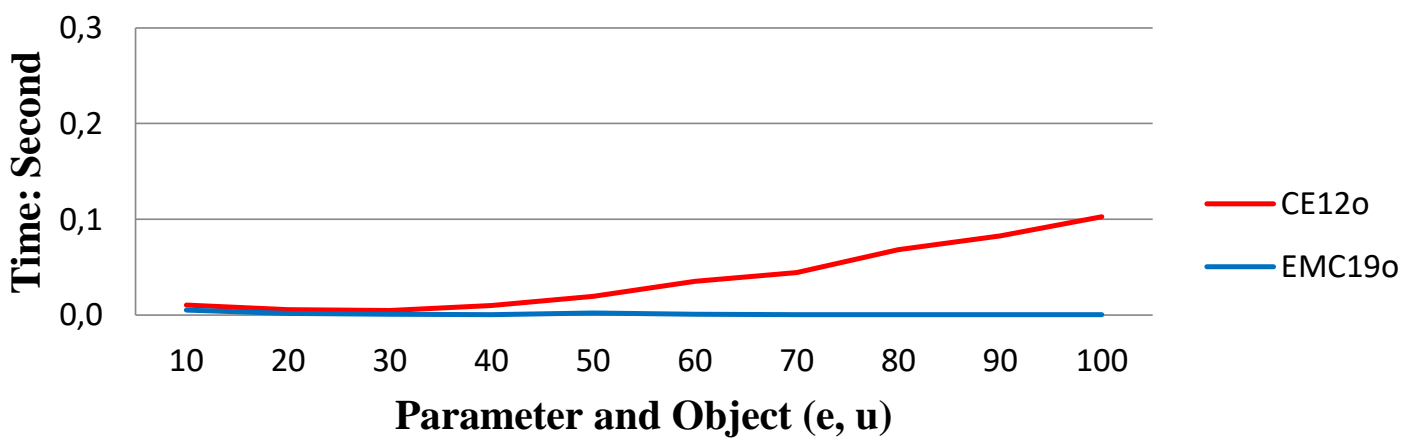

Figure 11. The figure for Table 11

We then give their running times in Table 12 and Fig. 12 for the parameters and the objects ranging from 100 to 1000. 0.0201-second and 637-second running times shows EMC19o is more appropriate than CE12o for any real-time software 
Table 12. The running times of the methods for 100-1000 objects and parameters (In Second)

\begin{tabular}{lcccccccccc}
\hline Parameter Count & $\mathbf{1 0 0}$ & $\mathbf{2 0 0}$ & $\mathbf{3 0 0}$ & $\mathbf{4 0 0}$ & $\mathbf{5 0 0}$ & $\mathbf{6 0 0}$ & $\mathbf{7 0 0}$ & $\mathbf{8 0 0}$ & $\mathbf{9 0 0}$ & $\mathbf{1 0 0 0}$ \\
\hline CE12o & 0.1635 & 1.4368 & 6.5425 & 18.5807 & 42.0813 & 83.9797 & 151.8452 & 257.2460 & 415.8905 & 637.8363 \\
EMC190 & 0.0071 & 0.0037 & 0.0034 & 0.0048 & 0.0083 & 0.0089 & 0.0113 & 0.0137 & 0.0162 & 0.0201 \\
Difference & 0.1564 & 1.4331 & 6.5392 & 18.5760 & 42.0731 & 83.9708 & 151.8339 & 257.2323 & 415.8743 & 637.8162 \\
Advantage (\%) & 95.6327 & 99.7408 & 99.9485 & 99.9744 & 99.9804 & 99.9894 & 99.9925 & 99.9947 & 99.9961 & 99.9969 \\
\hline
\end{tabular}

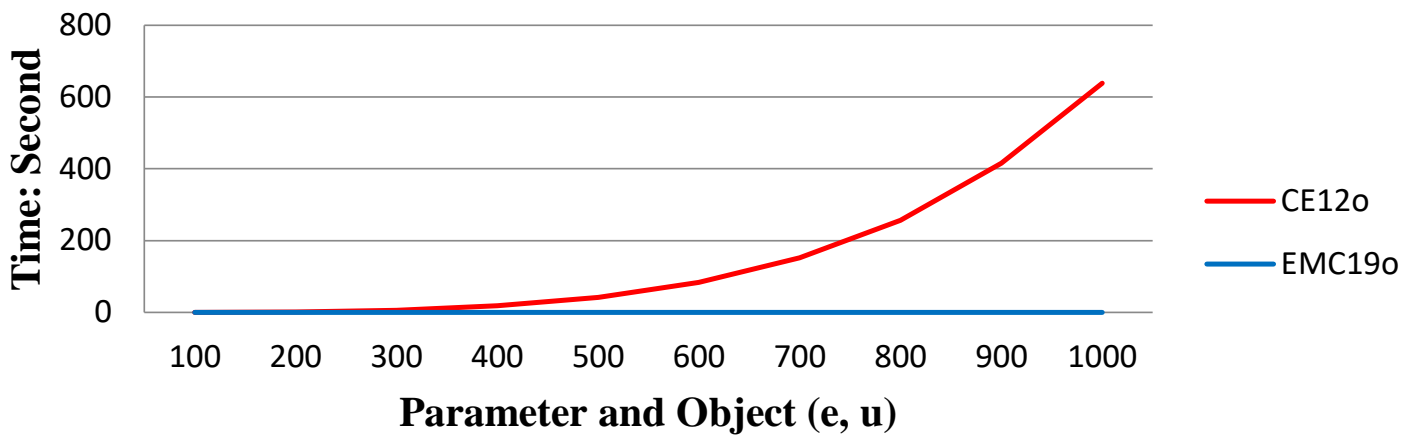

Figure 12. The figure for Table 12

The results show that EMC19o outperforms than CE12o in any number of data.

\section{An Application of EMC19o}

In this section, we apply EMC19o to sort some filters used in image denoising concerning noise removal performance. Even though sorting these filters is to be more difficult in the event that the filters perform variously in different noise densities, EMC19o overcomes this difficulty. To illustrate, let us consider mean-SSIM results (Table 13) and mean-PSNR results (Table 14) provided in [41].

Table 13. The mean-SSIM results of the filters for the 15 traditional images

\begin{tabular}{lccccccccc}
\hline Noise Density & $\mathbf{1 0 \%}$ & $\mathbf{2 0 \%}$ & $\mathbf{3 0 \%}$ & $\mathbf{4 0 \%}$ & $\mathbf{5 0 \%}$ & $\mathbf{6 0 \%}$ & $\mathbf{7 0 \%}$ & $\mathbf{8 0 \%}$ & $\mathbf{9 0 \%}$ \\
\hline PSMF & 0.9028 & 0.8715 & 0.8018 & 0.6988 & 0.4903 & 0.1882 & 0.0633 & 0.0318 & 0.0139 \\
DBA & 0.9079 & 0.8664 & 0.8097 & 0.7376 & 0.6521 & 0.5552 & 0.4567 & 0.3623 & 0.2937 \\
MDBUTMF & 0.8841 & 0.7994 & 0.7443 & 0.7657 & 0.7963 & 0.7880 & 0.7501 & 0.6443 & 0.3052 \\
NAFSM & 0.9147 & 0.8916 & 0.8669 & 0.8409 & 0.8124 & 0.7796 & 0.7403 & 0.6872 & 0.5736 \\
DAMF & 0.9253 & 0.9113 & 0.8946 & 0.8752 & 0.8523 & 0.8244 & 0.7892 & 0.7398 & 0.6572 \\
\hline
\end{tabular}

Table 14. The mean-PSNR results of the filters for the 15 traditional images

\begin{tabular}{lccccccccc}
\hline Noise Density & $\mathbf{1 0 \%}$ & $\mathbf{2 0 \%}$ & $\mathbf{3 0 \%}$ & $\mathbf{4 0 \%}$ & $\mathbf{5 0 \%}$ & $\mathbf{6 0 \%}$ & $\mathbf{7 0 \%}$ & $\mathbf{8 0 \%}$ & $\mathbf{9 0 \%}$ \\
\hline PSMF & 31.6100 & 28.3800 & 25.2900 & 22.2500 & 18.1900 & 12.6000 & 9.1700 & 7.4600 & 6.0800 \\
DBA & 32.8200 & 29.0500 & 26.1800 & 23.7200 & 21.4900 & 19.2700 & 17.0900 & 14.8100 & 12.1600 \\
MDBUTMF & 31.2400 & 28.0500 & 26.6800 & 26.7300 & 26.8400 & 26.1800 & 24.8600 & 21.4200 & 14.0700 \\
NAFSM & 33.8800 & 31.0500 & 29.3000 & 28.0400 & 26.9500 & 25.9300 & 24.8900 & 23.5900 & 20.7800 \\
DAMF & 37.4800 & 34.1400 & 31.9500 & 30.3000 & 28.9100 & 27.6300 & 26.3200 & 24.8000 & 22.7100 \\
\hline
\end{tabular}

Assume that the success in high noise densities is more important than in the others. In that case, the values given in Table 13 and the values normalized via maximum entry of Table 14 given in Table 14 can be represented with two $f p f s$-matrices as follows: 


$$
\left[a_{i j}\right]:=\left[\begin{array}{lllllllll}
0.1 & 0.2 & 0.3 & 0.4 & 0.5 & 0.6 & 0.7 & 0.8 & 0.9 \\
0.9028 & 0.8715 & 0.8018 & 0.6988 & 0.4903 & 0.1882 & 0.0633 & 0.0318 & 0.0139 \\
0.9079 & 0.8664 & 0.8097 & 0.7376 & 0.6521 & 0.5552 & 0.4567 & 0.3623 & 0.3623 \\
0.8841 & 0.7994 & 0.7443 & 0.7657 & 0.7963 & 0.7880 & 0.7501 & 0.6443 & 0.3052 \\
0.9147 & 0.8916 & 0.8669 & 0.8409 & 0.8124 & 0.7796 & 0.7403 & 0.6872 & 0.5736 \\
0.9253 & 0.9113 & 0.8946 & 0.8752 & 0.8523 & 0.8244 & 0.7892 & 0.7398 & 0.6572
\end{array}\right]
$$

and

$$
\left[b_{i k}\right]:=\left[\begin{array}{lllllllll}
0.1 & 0.2 & 0.3 & 0.4 & 0.5 & 0.6 & 0.7 & 0.8 & 0.9 \\
0.8434 & 0.7572 & 0.6748 & 0.5936 & 0.4853 & 0.3362 & 0.2447 & 0.1990 & 0.1622 \\
0.8757 & 0.7751 & 0.6985 & 0.6329 & 0.5734 & 0.5141 & 0.4560 & 0.3951 & 0.3244 \\
0.8335 & 0.7484 & 0.7118 & 0.7132 & 0.7161 & 0.6985 & 0.6633 & 0.5715 & 0.3754 \\
0.9039 & 0.8284 & 0.7818 & 0.7481 & 0.7191 & 0.6918 & 0.6641 & 0.6294 & 0.5544 \\
1.0000 & 0.9109 & 0.8525 & 0.8084 & 0.7713 & 0.7372 & 0.7022 & 0.6617 & 0.6059
\end{array}\right]
$$

If we apply EMC19o to the $f p f s$-matrices $\left[a_{i j}\right]$ and $\left[b_{i k}\right]$, then the score matrix and the decision set are as follows:

$$
\left[s_{i 1}\right]=\left[\begin{array}{lllll}
0.2795 & 0.3331 & 0.5251 & 0.5498 & 0.5918
\end{array}\right]^{T}
$$

and

$$
\left\{{ }^{0.4723} \text { PSMF, }{ }^{0.5629} \text { DBA, }{ }^{0.8872} \text { MDBUTMF, }{ }^{0.9289} \text { NAFSM, }{ }^{1} \text { DAMF }\right\}
$$

The scores show that DAMF outperforms the others and the ranking order DAMF, NAFSM, MDBUTMF, DBA, and PSMF is valid.

Assume that the success in low noise densities is more important than in the others. In that case, the values given in Table 13 and the values normalized via maximum entry of Table 14 given in Table 14 can be represented with two $f p f s$-matrices as follows:

$$
\left[c_{i j}\right]:=\left[\begin{array}{lllllllll}
0.9 & 0.8 & 0.7 & 0.6 & 0.5 & 0.4 & 0.3 & 0.2 & 0.1 \\
0.9028 & 0.8715 & 0.8018 & 0.6988 & 0.4903 & 0.1882 & 0.0633 & 0.0318 & 0.0139 \\
0.9079 & 0.8664 & 0.8097 & 0.7376 & 0.6521 & 0.5552 & 0.4567 & 0.3623 & 0.3623 \\
0.8841 & 0.7994 & 0.7443 & 0.7657 & 0.7963 & 0.7880 & 0.7501 & 0.6443 & 0.3052 \\
0.9147 & 0.8916 & 0.8669 & 0.8409 & 0.8124 & 0.7796 & 0.7403 & 0.6872 & 0.5736 \\
0.9253 & 0.9113 & 0.8946 & 0.8752 & 0.8523 & 0.8244 & 0.7892 & 0.7398 & 0.6572
\end{array}\right]
$$

and

$$
\left[d_{i k}\right]:=\left[\begin{array}{lllllllll}
0.9 & 0.8 & 0.7 & 0.6 & 0.5 & 0.4 & 0.3 & 0.2 & 0.1 \\
0.8434 & 0.7572 & 0.6748 & 0.5936 & 0.4853 & 0.3362 & 0.2447 & 0.1990 & 0.1622 \\
0.8757 & 0.7751 & 0.6985 & 0.6329 & 0.5734 & 0.5141 & 0.4560 & 0.3951 & 0.3244 \\
0.8335 & 0.7484 & 0.7118 & 0.7132 & 0.7161 & 0.6985 & 0.6633 & 0.5715 & 0.3754 \\
0.9039 & 0.8284 & 0.7818 & 0.7481 & 0.7191 & 0.6918 & 0.6641 & 0.6294 & 0.5544 \\
1.0000 & 0.9109 & 0.8525 & 0.8084 & 0.7713 & 0.7372 & 0.7022 & 0.6617 & 0.6059
\end{array}\right]
$$

If we apply EMC19o to the $f p f s$-matrices $\left[c_{i j}\right]$ and $\left[d_{i k}\right]$, then the score matrix and the decision set are as follows:

$$
\left[s_{i 1}\right]=\left[\begin{array}{lllll}
0.8125 & 0.8171 & 0.7957 & 0.8232 & 0.8328
\end{array}\right]^{T}
$$

and

$$
\left\{{ }^{0.9757} \text { PSMF, }{ }^{0.9812} \text { DBA, }{ }^{0.9555} \text { MDBUTMF, }{ }^{0.9885} \text { NAFSM, }{ }^{1} \text { DAMF }\right\}
$$

The scores show that DAMF outperforms the others and the ranking order DAMF, NAFSM, DBA, PSMF, and MDBUTMF is valid. 


\section{Conclusion}

The soft max-min decision-making method SMmDM was defined in 2010 [5] and the fuzzy soft max-min decision-making method FSMmDM [12], being a generalisation of SMmDM, was defined in 2012. Lately, since such methods cannot model decision-making problems in the event that the parameters have uncertainties, these methods have been configured [34] via $f p f s$-matrices [13,40]. However, the configured method has a drawback such as its incapability of processing a large number of parameters on such a standard computer with $2.6 \mathrm{GHz}$ i5 Dual Core CPU and 4GB RAM.

In this study, we have proposed the method EMC19a, which is faster than CE12a and the method EMC19o, which is faster than CE12o. Of course, for other products, simplifications of these methods can be investigated.

Also, we have compared the methods mentioned above in terms of their running times. Besides the results in Section 6, the results in Table 15 and 16 too show that EMC19a and EMC19o perform better than CE12a and CE12o, respectively.

Table 15. The mean advantage, max advantage, and max difference values of EMC19a over CE12a

\begin{tabular}{lllccc}
\hline Location & Objects & Parameters & Mean Advantage \% & Max Advantage \% & Max Difference \\
\hline Table 1 & 10 & $10-100$ & 81.9602 & 98.5428 & 0.0162 \\
Table 2 & 10 & $1000-10000$ & 99.8809 & 99.9991 & 278.8835 \\
Table 3 & $10-100$ & 10 & 70.6767 & 85.0085 & 0.0067 \\
Table 4 & $1000-$ & 10 & 92.7738 & 95.8986 & 1.8979 \\
Table 5 & $10-100$ & $10-100$ & 87.5239 & 99.2141 & 0.0897 \\
Table 6 & $100-1000$ & $100-1000$ & 99.2576 & 99.9967 & 616.6662 \\
\hline
\end{tabular}

Table 16. The mean advantage, max advantage, and max difference values of EMC19o over CE12o

\begin{tabular}{lllccc}
\hline Location & Objects & Parameters & Mean Advantage \% & Max Advantage \% & Max Difference \\
\hline Table 7 & 10 & $10-100$ & 82.9999 & 98.8234 & 0.0200 \\
Table 8 & 10 & $1000-10000$ & 99.9089 & 99.9995 & 515.0036 \\
Table 9 & $10-100$ & 10 & 73.1805 & 90.7323 & 0.0056 \\
Table 10 & $1000-$ & 10 & 93.6895 & 96.2443 & 2.0905 \\
Table 11 & $10-100$ & $10-100$ & 87.7767 & 99.3082 & 0.1023 \\
Table 12 & $100-1000$ & $100-1000$ & 99.5246 & 99.9969 & 637.8162 \\
\hline
\end{tabular}

Finally, it is clear that the methods constructed by minimum-maximum (min-max), max-max, and min-min decision functions are also worth to study.

\section{Acknowledgements}

The authors thank Dr. Uğur Erkan for technical support. This work was supported by the Office of Scientific Research Projects Coordination at Çanakkale Onsekiz Mart University, Grant number: FBA-2018-1367. 


\section{References}

[1]. Molodtsov, D., Soft set theory-first results, Computers and Mathematics with Applications, 1999, 37(4-5), 19-31.

[2]. Maji, P. K., Biswas, R., Roy, A. R., Fuzzy soft sets, The Journal of Fuzzy Mathematics, 2001, 9(3), 589-602.

[3]. Maji, P. K., Roy, A. R., Biswas, R., An application of soft sets in a decision making problem, Computer and Mathematics with Applications, 2002, 44(8-9), 1077-1083.

[4]. Maji, P. K., Biswas, R., Roy, A. R., Soft set theory, Computer and Mathematics with Applications, 2003, 45(4-5), 555-562.

[5]. Çağman, N., Enginoğlu, S., Soft matrix theory and its decision making, Computer and Mathematics with Applications, 2010, 59(10), 3308-3314.

[6]. Çağman, N., Enginoğlu, S., Soft set theory and uni-int decision making, European Journal of Operational Research, 2010, 207(2), 848-855.

[7]. Çağman, N., Çıtak, F., Enginoğlu, S., Fuzzy parameterized fuzzy soft set theory and its applications, Turkish Journal of Fuzzy Systems, 2010, 1(1), 21-35.

[8]. Çağman, N., Çıtak, F., Enginoğlu, S., FP-soft set theory and its applications, Annals of Fuzzy Mathematics and Informatics, 2011, 2(2), 219-226.

[9]. Çağman, N., Enginoğlu, S., Çıtak, F., Fuzzy soft set theory and its applications, Iranian Journal of Fuzzy Systems, 2011, 8(3), 137-147.

[10]. Çağman, N., Deli, İ., Means of FP-soft sets and their applications, Hacettepe Journal of Mathematics and Statistics, 2012, 41(5), 615-625.

[11]. Çağman, N., Deli, İ., Products of FP-soft sets and their applications, Hacettepe Journal of Mathematics and Statistics, 2012, 41(3), 365-374.

[12]. Çağman, N., Enginoğlu, S., Fuzzy soft matrix theory and its application in decision making, Iranian Journal of Fuzzy Systems, 2012, 9(1), 109-119.

[13]. Enginoğlu, S., Soft matrices, Doctoral Dissertation, Gaziosmanpaşa University, Tokat, Turkey 2012.

[14]. Atmaca, S., Zorlutuna, İ., On topological structures of fuzzy parametrized soft sets, The Scientific World Journal, 2014, Article ID 164176, 8 pages.

[15]. Deli, İ., Çağman, N., Relations on FP-soft sets applied to decision making problems, Journal of New Theory, 2015, 3, 98-107.

[16]. Çıtak, F., Çağman, N., Soft int-rings and its algebraic applications, Journal of Intelligent and Fuzzy Systems, 2015, 28, 1225-1233.

[17]. Enginoğlu, S., Çağman, N., Karataş, S., Aydın, T., On soft topology, El-Cezerî Journal of Science and Engineering, 2015, 2(3), 23-38.

[18]. Karaaslan, F., Soft classes and soft rough classes with applications in decision making, Mathematical Problems in Engineering, 2016, Article ID 1584528, 11 pages.

[19]. Muştuoğlu, E., Sezgin, A., Türk, Z. K., Some characterizations on soft uni-groups and normal soft uni-groups, International Journal of Computer Applications, 2016, 155(10), 1-8.

[20]. Sezgin, A., A new approach to semigroup theory I: Soft union semigroups, ideals and bi-ideals, Algebra Letters, 2016, 2016(3), 1-46.

[21]. Şenel, G., A new approach to Hausdorff space theory via the soft sets, Mathematical Problems in Engineering, 2016, Article ID 2196743, 6 pages.

[22]. Tunçay, M., Sezgin, A., Soft union ring and its applications to ring theory, International Journal of Computer Applications, 2016, 151(9), 7-13.

[23]. Zorlutuna, İ., Atmaca, S., Fuzzy parametrized fuzzy soft topology, New Trends in Mathematical Sciences, 2016, 4(1), 142-152. 
[24]. Atmaca, S., Relationship between fuzzy soft topological spaces and $\left(X, \tau_{e}\right)$ parameter spaces, Cumhuriyet Science Journal, 2017, 38(4), Supplement, 813-821.

[25]. Bera, S., Roy, S. K., Karaaslan, F., Çağman, N., Soft congruence relation over lattice, Hacettepe Journal of Mathematics and Statistics, 2017, 46(6), 1035-1042.

[26]. Çıtak, F., Çağman, N., Soft k-int-ideals of semirings and its algebraic structures, Annals of Fuzzy Mathematics and Informatics, 2017, 13(4), 531-538.

[27]. Riaz, M., Hashmi, R., Fuzzy parameterized fuzzy soft topology with applications, Annals of Fuzzy Mathematics and Informatics, 2017, 13(5), 593-613.

[28]. Şenel, G., A comparative research on the definition of soft point, International Journal of Computer Applications, 2017, 163(2), 1-4.

[29]. Riaz, M., Hashmi, R., Fuzzy parameterized fuzzy soft compact spaces with decision-making, Punjab University Journal of Mathematics, 2018, 50(2), 131-145.

[30]. Riaz, M., Hashmi, R., Farooq, A., Fuzzy parameterized fuzzy soft metric spaces, Journal of Mathematical Analysis, 2018, 9(2), 25-36.

[31]. Şenel, G., Analyzing the locus of soft spheres: Illustrative cases and drawings. European Journal of Pure and Applied Mathematics, 2018, 11(4), 946-957.

[32]. Ullah, A., Karaaslan, F., Ahmad, I., Soft uni-Abel-Grassmann's groups, European Journal of Pure and Applied Mathematics, 2018, 11(2), 517-536.

[33]. Sezgin, A., Çağman, N., Çıtak, F., $\alpha$-Inclusions applied to group theory via soft set and logic, Communications Faculty of Sciences University of Ankara Series A1 Mathematics and Statistics, 2019, 68(1), 334-352.

[34]. Enginoğlu, S., Memiş, S. A configuration of some soft decision-making algorithms via $f p f s$ matrices, Cumhuriyet Science Journal, 2018, 39(4), 871-881.

[35]. Enginoglu, S., Memiş, S., Comment on "Fuzzy soft sets" [The Journal of Fuzzy Mathematics, 9(3), 2001, 589-602], International Journal of Latest Engineering Research and Applications, 2018, 3(9), 1-9.

[36]. Enginoğlu, S., Memiş, S., A review on an application of fuzzy soft set in multicriteria decision making problem [P.K. Das, R. Borgohain, International Journal of Computer Applications 38 (12) (2012) 33-37]. In: Akgül, M., Y1lmaz, İ., İpek, A. (eds.) Proceeding of The International Conference on Mathematical Studies and Applications 2018, pp. 173-178, Karaman, Turkey.

[37]. Enginoğlu, S., Memiş, S., A review on some soft decision-making methods. In: Akgül, M., Y1lmaz, İ., İpek, A. (eds.) Proceeding of The International Conference on Mathematical Studies and Applications 2018, pp. 437-442, Karaman, Turkey.

[38]. Enginoglu, S., Memiş, S., Arslan, B., Comment (2) on soft set theory and uni-int decision making [European Journal of Operational Research, (2010) 207, 848-855], Journal of New Theory, 2018, 25, 85-102.

[39]. Enginoglu, S., Memiş, S., Öngel, T., Comment on soft set theory and uni-int decision making [European Journal of Operational Research, (2010) 207, 848-855], Journal of New Results in Science, 2018, 7(3), 28-43.

[40]. Enginoğlu, S., Çağman, N., Fuzzy parameterized fuzzy soft matrices and their application in decision-making, TWMS Journal of Applied and Engineering Mathematics, In Press.

[41]. Erkan, U., Gökrem, L., Enginoğlu, S., Different applied median filter in salt and pepper noise, Computers and Electrical Engineering, 2018, 70, 789-798. 